\title{
Rate Constant of the
} Reaction of Chlorine Atoms with Methanol over the Temperature Range 291-475 K

\section{E. W. KAISER, ${ }^{1}$ T. J. WALLINGTON²}

${ }^{1}$ Department of Natural Sciences, University of Michigan-Dearborn, Dearborn, MI 48128

${ }^{2}$ System Analytics and Environmental Science Department, Research and Innovation Center, Ford Motor Company, Mail Drop RIC-2122, Dearborn, MI 48121-2053

Received 16 September 2009; revised 14 October 2009; accepted 20 October 2009

DOI 10.1002/kin.20474

Published online in Wiley InterScience (www.interscience.wiley.com).

\begin{abstract}
The rate constant of the reaction $\mathrm{Cl}+\mathrm{CH}_{3} \mathrm{OH}\left(k_{1}\right)$ has been measured in 500-950 Torr of $\mathrm{N}_{2}$ over the temperature range $291-475 \mathrm{~K}$. The rate constant determination was carried out using the relative rate technique with $\mathrm{C}_{2} \mathrm{H}_{6}$ as the reference compound. Experiments were performed by irradiating mixtures of $\mathrm{CH}_{3} \mathrm{OH}, \mathrm{C}_{2} \mathrm{H}_{6}, \mathrm{Cl}_{2}$, and $\mathrm{N}_{2}$ with UV light from a fluorescent lamp whose intensity peaked near $360 \mathrm{~nm}$. The resultant temperature-dependent rate expression is $k_{1}=8.6( \pm 1.3) \times 10^{-11} \exp -167( \pm 60) / \mathrm{T} \mid \mathrm{cm}^{3}$ molecule $\mathrm{c}^{-1} \mathrm{~s}^{-1}$. Error limits represent data scatter $(2 \sigma)$ in the current experiments and do not include error in the reference rate constant. (c) 2009 Wiley Periodicals, Inc. Int J Chem Kinet 42: 113-1 16, 2010
\end{abstract}

\section{INTRODUCTION}

The rate constant for the reaction of $\mathrm{Cl}$ atoms with methanol has been studied extensively at

$$
\mathrm{CH}_{3} \mathrm{OH}+\mathrm{Cl}=\text { products }
$$

ambient temperature by both absolute and relative rate methods as discussed in [1]. There have been only two measurements of the temperature dependence of $k_{1}$, both by absolute methods, and these values differ

\footnotetext{
Correspondence to: E. W. Kaiser; e-mail: ewkaiser@ comcast.net.

(c) 2009 Wiley Periodicals, Inc.
}

substantially [1]. The data of Michael et al. [2] suggest that $k_{1}$ has no temperature dependence to within experimental uncertainty over the temperature range 200-500 K, whereas those of Garzón et al. [3] show a significant Arrhenius temperature dependence for $k_{1}$ over the range 266-380 K.

Because of the significant difference in these activation energies, we have undertaken a measurement of $k_{1}$ over the temperature range $291-475 \mathrm{~K}$ at pressures ranging from 500 to 950 Torr. These measurements use the relative rate technique with $\mathrm{C}_{2} \mathrm{H}_{6}$ as the reference species. The temperature dependence of the rate constant for the reference reaction $\left(k_{2}\right)$

$$
\mathrm{C}_{2} \mathrm{H}_{6}+\mathrm{Cl}=\text { products }
$$


has been examined in detail by Bryukov et al. [4], resulting in a non-Arrhenius expression that includes all available temperature-dependent data up to and including those of Bryukov et al. of $k_{2}=\left(7.23 \times 10^{-13}\right)$ $T^{0.70} \exp (+117 / T) \mathrm{cm}^{3}$ molecule $\mathrm{c}^{-1} \mathrm{~s}^{-1}$. At $298 \mathrm{~K}$, this gives a value of $5.78 \times 10^{-11}$, which is slightly smaller than the current value at $298 \mathrm{~K}\left(5.9 \times 10^{-11}\right)$, which is based on an evaluation of a large body of data in [1]. We chose to adjust the expression of Bryukov et al. by 5.9/5.78, resulting in a final value of $k_{2}=\left(7.38 \times 10^{-13}\right) T^{0.70} \exp (+117 / T)$. This was the expression used to calculate values of $k_{1}$ from the relative rate ratios. We believe that ethane is an ideal choice as the reference compound because the rate constants of ethane and methanol are very similar in magnitude throughout the temperature range studied, and $k_{2}$ has been examined over a very wide temperature range as discussed in [4].

\section{EXPERIMENTAL}

The reactant mole fractions in these experiments were measured using a GC/FID system, which has been described elsewhere [5]. The GC temperature program used in these analyses on a 30-m DB-1 column with $5-\mu \mathrm{m}$ coating was $35^{\circ} \mathrm{C}(3 \mathrm{~min}) ; 20^{\circ} \mathrm{C} / \mathrm{min}$ to $65^{\circ} \mathrm{C}$; hold $0.3 \mathrm{~min}, 38^{\circ} \mathrm{C} / \mathrm{min}$ to $155^{\circ} \mathrm{C}$ and hold. Reactant retention times are $\mathrm{CH}_{4}(1.92 \mathrm{~min}), \mathrm{C}_{2} \mathrm{H}_{6}$ (2.16 min), and $\mathrm{CH}_{3} \mathrm{OH}$ (3.42 $\left.\mathrm{min}\right)$. The experiments were performed using $\mathrm{Cl}_{2}(99.7 \%) / \mathrm{CH}_{3} \mathrm{OH}$ (99\%)/ $\mathrm{CH}_{4}$ (research) $/ \mathrm{C}_{2} \mathrm{H}_{6}$ (research) mixtures in $\mathrm{N}_{2}$ (UHP) diluent (freeze/thaw degassing cycles were performed on the methanol and $\mathrm{Cl}_{2}$ reactants). Methane was used for internal calibration of the $\mathrm{GC}$ analysis since it is essentially unreactive toward $\mathrm{Cl}\left(k_{\mathrm{CH}_{4}}=1.04\right.$ and $7.2 \times 10^{-13} \mathrm{~cm}^{3}$ molecule $\mathrm{s}^{-1}$ at 297 and $475 \mathrm{~K}$, respectively [6]) relative to methanol or ethane. Ethane (research) was added as a reference compound in these relative rate experiments to measure the temperature dependence of the overall rate coefficient for reaction (1).

The experiments were performed in a $\sim 40-\mathrm{cm}^{3}$, cylindrical, Pyrex reactor (26-mm ID $\times \sim 7$-cm length) with a thermocouple well along the axis and a Teflonsealed, glass stopcock attached to a Pyrex capillary tube at the end opposite the thermocouple well. The reactor was placed inside a tube oven, whose lid was open approximately $6 \mathrm{~mm}$ to allow radiation from the fluorescent lamp to enter. The calibration of the chromelalumel thermocouple was checked in ice and boiling water. The temperature along the axis of the reactor was uniform to $\sim 3 \mathrm{~K}$ from the mean at $475 \mathrm{~K}$. During a reaction, the unreacted mixture was placed into the reactor at pressures varying from 500 to 950 Torr depending on the depletion in the reactant storage flask from which the reactor was filled. Chlorine atoms were generated by irradiation of the unreacted mixture with UV light (peak at $\sim 360 \mathrm{~nm}$ ) using a single Sylvania F6T5 BLB fluorescent lamp. After a chosen irradiation time, a portion of the contents of the reactor was removed into a $2.5-\mathrm{cm}^{3}$ gas-tight syringe preset to $1-\mathrm{cm}^{3}$ sample volume and analyzed by direct injection of this sample into the injector port (at $373 \mathrm{~K}$ ) of the gas chromatograph. Only one irradiation and sample removal was possible per reactor fill in these experiments because a substantial fraction of the initial mixture in the reactor was lost during the sampling process.

Before and after each irradiation experiment, the reactor was filled and the unirradiated mixture was allowed to remain in the reactor for a time similar to the irradiation experiment. No reaction was observed without irradiation based on the absence of $\mathrm{C}_{2} \mathrm{H}_{5} \mathrm{Cl}$ in the sample gas and the lack of measurable consumption of the reactants. These experiments in the absence of irradiation were used to provide baseline measurements of the initial mole fractions in the unreacted mixture. Repeat measurements are very important because methanol can be adsorbed on surfaces in the sampling system. Thus, having multiple measurements of the unreacted mixture is essential to obtaining accurate measurements of the consumption of methanol. In the experiments with irradiation, only one sample was obtained as stated above. In this case, repeating the entire fill and irradiation process was necessary for checking reproducibility. At least three irradiation experiments were carried out at each temperature. The reactant mole fractions were $\mathrm{Cl}_{2}(975 \mathrm{ppm}), \mathrm{CH}_{3} \mathrm{OH}$ (140 ppm), $\mathrm{CH}_{4}(130 \mathrm{ppm}), \mathrm{C}_{2} \mathrm{H}_{6}(100 \mathrm{ppm})$, and balance $\mathrm{N}_{2}$. The presence of $\mathrm{CH}_{4}$ as an internal calibrant permitted corrections to be made for uncertainty in the precise amount of sample injected into the GC using the syringe.

\section{RESULTS AND DISCUSSION}

Table I presents the rate constant ratios measured at six temperatures. A new mixture with the same nominal composition was prepared in the reactant storage flask for each temperature presented in the table. Each entry represents a separate fill and irradiation of the reactor. The table shows the fractional consumption of methanol $\left(C / C_{0}\right)$ during each experiment, the irradiation time, the measured rate constant ratio, the calculated value of $k_{2}$, and the value of $k_{1}$ determined from $k_{2}$ and $k_{1} / k_{2}$. As the methanol consumption increases as shown in Table I, the pressure in the reactor decreases 


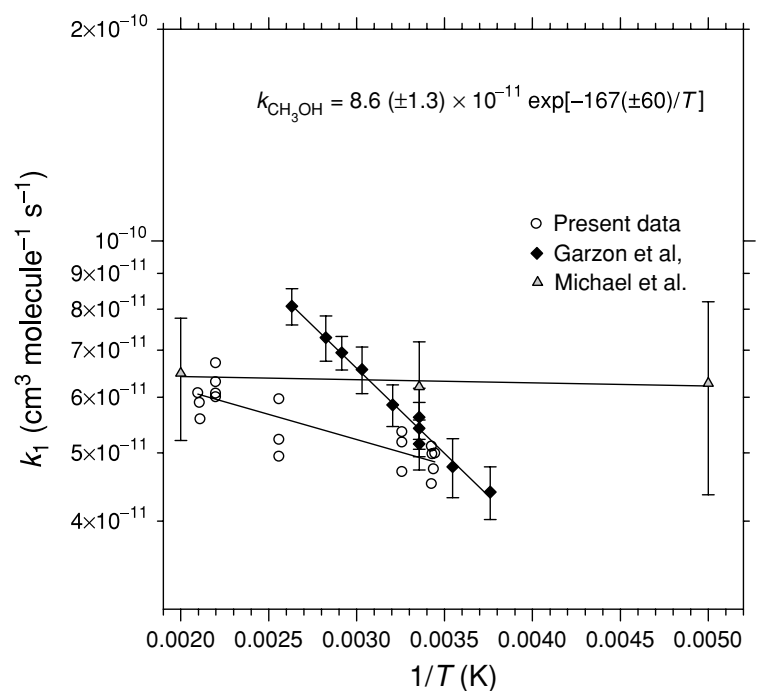

Figure 1 Rate constant of the reaction of $\mathrm{Cl}$ atoms with $\mathrm{CH}_{3} \mathrm{OH}$ as a function of temperature. Circles are data from the current relative rate experiments. Multiple data points at the same temperature are results for different fractional consumption of methanol (see Table I). Triangles are absolute rate data from [2]; diamonds are absolute rate data from [3].

(over the range from $\sim 950$ to 500 Torr) because of depletion of the reactant storage flask as discussed in the Experimental section. Four data points were taken at $455 \mathrm{~K}$, and inspection of these data shows that over this pressure range, no systematic change occurs in the rate constant ratios as expected for abstraction reactions.

Figure 1 presents a plot of the values of $k_{1}$ (circles) in Table I as a function of the reciprocal of the temperature. Fitting an Arrhenius expression to these 18 data points using the least-squares method yields the temperature-dependent rate expression $k_{1}=8.6( \pm 1.3) \times 10^{-11} \exp [-167( \pm 60) / T] \mathrm{cm}^{3}$ molecule ${ }^{-1} \mathrm{~s}^{-1}$. The error limits are $2 \sigma$ as calculated by the fitting program. These errors do not include uncertainty in $k_{2}$. Based on the IUPAC evaluation [1], which uses an Arrhenius expression $\left(k_{2}=8.3 \times 10^{-11}\right.$ $\exp [-100 / T)]$, the error in the temperature dependence $E_{\mathrm{a}} / R= \pm 100 \mathrm{~K}$ for $k_{2}$. Combining this error in $E_{\mathrm{a}}\left(k_{2}\right) / R$ with the data scatter in the relative rate experiments, we estimate that the activation energy of $k_{1}$ is $E_{\mathrm{a}}\left(k_{1}\right) / R=167 \pm 160 \mathrm{~K}$. This indicates that $E_{\mathrm{a}} / R<330 \mathrm{~K}$. If the uncertainty in the temperature dependence of $k_{2}$ can be reduced in the future, the upper limit to the activation energy of $k_{1}$ using the present data will also be reduced.

Also plotted in Fig. 1 are the data of Michael et al. [2] (triangles) and Garzón et al. [3] (diamonds) including the error estimates of the authors that are $2 \sigma$. Garzón et al. quote a temperature-dependent rate constant of $k_{1}=3.55( \pm 0.22) \times 10^{-11} \exp [-559$ $( \pm 40) / T$ ] over the range $266-380 \mathrm{~K}$ (errors are stated to represent $2 \sigma$ ). Michael et al. published a rate constant independent of temperature of $6.33( \pm 1.4) \times$ $10^{-11} \mathrm{~cm}^{3}$ molecule $\mathrm{e}^{-1} \mathrm{~s}^{-1}$ in which the error is $2 \sigma$. The temperature range encompassed by the data of Michael et al. $(200,298$, and $500 \mathrm{~K})$ is the largest of the three data sets in Fig. 1. An estimate of the largest positive activation energy from the Michael et al. data can be obtained by drawing a straight line between the maximum of the error bar at $500 \mathrm{~K}$ to the minimum of the error bar at $200 \mathrm{~K}$. This line would represent an activation energy of $E_{\mathrm{a}} / R=200 \mathrm{~K}$ for $k_{1}$, which is one-third of that measured by Garzón et al. As stated in the preceding paragraph, the upper limit derived from the current data is $E_{\mathrm{a}} / R<330 \mathrm{~K}$, which is $40 \%$ less

Table I Rate Constant of Reaction (1) (Cl + Methanol) Relative to That of $\mathrm{C}_{2} \mathrm{H}_{6}$ as a Function of Temperature ${ }^{a}$

\begin{tabular}{|c|c|c|c|c|}
\hline$T(\mathrm{~K})$ & $C / C_{0}$ & $k_{1} / k_{2}$ & 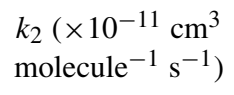 & 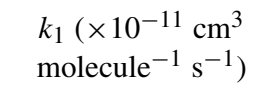 \\
\hline 475 & $\begin{array}{l}0.22,0.57,0.65 \\
75 \mathrm{~s}, 40 \mathrm{~s}, 27 \mathrm{~s}^{b}\end{array}$ & $0.835,0.86,0.792$ & 7.06 & $5.9,6.09,5.59$ \\
\hline 455 & $\begin{array}{c}0.28,0.34,0.53,0.65 \\
85 \mathrm{~s}, 70 \mathrm{~s}, 41 \mathrm{~s}, 27 \mathrm{~s}\end{array}$ & $0.97,0.867,0.877,0.911$ & 6.93 & $6.71,6.01,6.08,6.31$ \\
\hline 391 & $\begin{array}{c}0.333,0.367,0.639 \\
90 \mathrm{~s}, 80 \mathrm{~s}, 40 \mathrm{~s}\end{array}$ & $0.918,0.804,0.761$ & 6.50 & $5.97,5.23,4.95$ \\
\hline 307 & $\begin{array}{l}0.30,0.44,0.66 \\
75 \mathrm{~s}, 75 \mathrm{~s}, 30 \mathrm{~s}\end{array}$ & $0.90,0.79,0.87$ & 5.96 & $5.34,4.70,5.18$ \\
\hline 292 & $\begin{array}{c}0.318,0.538,0.725 \\
75 \mathrm{~s}, 40 \mathrm{~s}, 30 \mathrm{~s}\end{array}$ & $0.872,0.810,0.771$ & 5.86 & $5.11,4.74,4.52$ \\
\hline 291 & $\begin{array}{l}0.42,0.56 \\
65 \mathrm{~s}, 40 \mathrm{~s}\end{array}$ & $0.851,0.853$ & 5.86 & $5.0,5.01$ \\
\hline
\end{tabular}

${ }^{a} C / C_{0}=$ Fractional consumption of methanol; individual rate constant ratios listed in order of $C / C_{0}$.

${ }^{b}$ Irradiation time for each value of $C / C_{0}$ in seconds. 


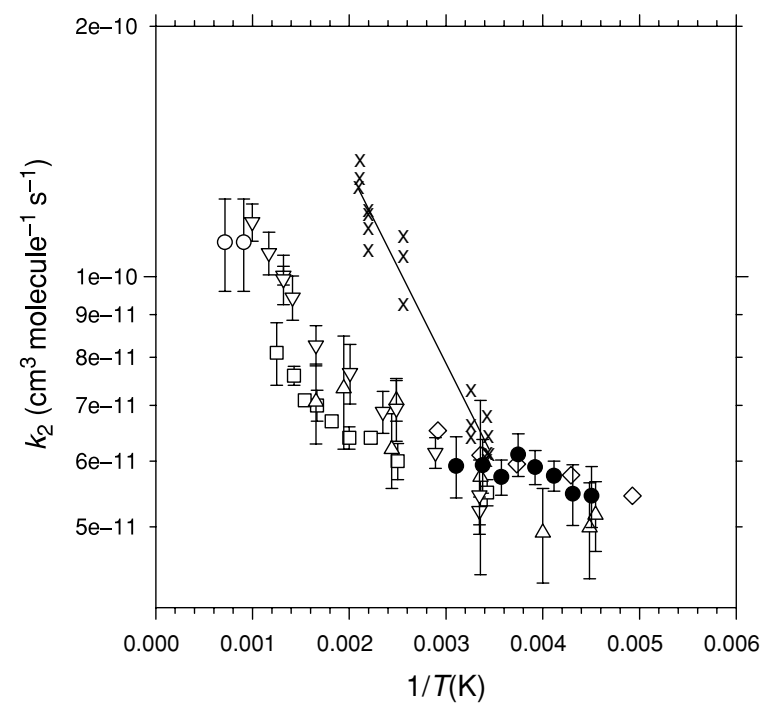

Figure 2 Temperature-dependent measurements of $k_{2}\{\mathrm{Cl}$ $\left.+\mathrm{C}_{2} \mathrm{H}_{6}\right\}$ : open circles, 1100-1400 K [11]; squares, 292$800 \mathrm{~K}$ [10]; inverted triangles, 299-1002 K [4]; diamonds, 203-343 K [9]; filled circles, 222-322 K [7]; triangles, 220$604 \mathrm{~K}$ [8]; symbol $\times$, calculated from Eq. (A); line = linearleast squares fit to these data points.

than that of Garzón et al. Based on these comparisons, it is likely that the activation energy of $k_{1}$ has been overestimated by Garzón et al.

Another test of the temperature-dependent measurements of $k_{1}$ by Garzón et al. can be carried out using their expression for $k_{1}$ with the relative rate values in the current experiments to calculate $k_{2}$. This provides values of $k_{2}$ at the five temperatures in Table I for comparison with published temperature-dependent measurements of $k_{2}$. Figure 2 presents all measurements of the temperature dependence of the rate constant for reaction (2) of which we are aware [4,7-11]. Figure 2 also includes the calculated temperature dependence of reaction (2) based on the current relative rate measurements and the measured temperature dependence of reaction (1) from the data of Garzón et al. [3] using the following equation:

$$
\begin{aligned}
k_{2} & =k_{1}(\text { Ref. [3] }) \times k_{2} / k_{1}(\text { this work }) \\
& =\left\{3.55 \times 10^{-11} \exp [-559 / T]\right\} \times k_{2} / k_{1} .
\end{aligned}
$$

The values of $k_{2}$ calculated from Eq. (A) for each measured rate constant ratio are shown by the symbol $\mathrm{X}$ in Fig. 2. The error limit for $k_{1}$ ( [3]) is stated to be $\sim \pm 8 \%$ $(2 \sigma)$ over the temperature range $266-380 \mathrm{~K}$, whereas the uncertainty in the $k_{2} / k_{1}$ (this work) is shown by the data scatter of the individual points. The values calculated for $k_{2}$ using this method are much higher than the other existing measurements of $k_{2}$ for temperatures above ambient, again indicating that $k_{1}$ from [3] has a temperature dependence that is too large. Combining the current data with those of Michael et al. results in a value for $E_{\mathrm{a}} / R$ for reaction (1) of $100 \pm 150 \mathrm{~K}$. Additional measurements of this rate constant as a function of temperature would be helpful in reducing the experimental uncertainty.

We acknowledge critical assistance provided by Prof. Craig Donahue at the University of Michigan-Dearborn.

\section{BIBLIOGRAPHY}

1. Atkinson, R.; Baulch, D. L.; Cox, R. A.; Crowley, J. N.; Hampson, R. F.; Hynes, R. G.; Jenkin, M. E.; Rossi, M. J.; Troe, J. Atmos Chem Phys 2006, 6, 3625.

2. Michael, J. V.; Nava, D. F.; Payne, W.A.; Stief, L. J. J Chem Phys 1979, 70, 3652.

3. Garzón, A.; Cuevas, C. A.; Ceacero, A. A.; Notario, A.; Albaladejo, J.; Fernando-Gomez, M. J Chem Phys 2006, $125,104305$.

4. Bryukov, M. G.; Slagle, I. R.; Knyazev, V. D. J Phys Chem A 2003, 107, 6565.

5. Kaiser, E. W.; Donahue, C. J.; Pala, I. R.; Wallington, T. J.; Hurley, M. D. J Phys Chem A 2007, 111, 1286.

6. Bryukov, M. G.; Slagle, I. R.; Knyazev, V. D. J Phys Chem A 2002, 106, 10532.

7. Manning, R. G.; Kurylo, M. J. J Phys Chem 1977, 81, 291.

8. Lewis, R. S.; Sander, S. P.; Wagner, S.; Watson, R. T. J Phys Chem 1980, 84, 2009.

9. Dobis, O.; Benson, S. W. J Am Chem Soc 1991, 113, 6377.

10. Pilgrim, J. S.; McIlroy, A.; Taatjes, C. A. J Phys Chem A 1997, 101, 1873.

11. Takahashi, K.; Yamamoto, O.; Inomata, T. Proc Comb Inst. 2002, 29, 2447. 